\title{
Healthcare Financing Administration Common Procedure Coding System
}

National Cancer Institute

\section{Source}

National Cancer Institute. Healthcare Financing Administration Common Procedure

Coding System. NCI Thesaurus. Code C132306.

A standardized coding system used by Medicare and other health insurance programs to ensure that claims are processed in an orderly and consistent manner. The coding system comprises the procedure codes of the American Medical Association Current Procedural Terminology (CPT) and an additional standardized coding set that is used primarily to identify products, supplies, and services not included in the CPT codes. 